\title{
Television Textuality
}

\author{
Textual Forms in Live Television Programming
}

\author{
GÖRAN BOLIN
}

\begin{abstract}
The article discusses the production of live television formats, as they have developed in Europe during the past decade. The analytical examples are taken from entertainment as well as factual television, and from public service as well as commercial contexts. In the article, it is argued that there has been an approximation between the textual features and generic and narrative structures of entertainment and factual live television, and a model is presented that is supposed to account for these narrative patterns.
\end{abstract}

Keywords: television production, formats, narration, genre, entertainment, factual programs, Sweden, election nights, Eurovision Song Contest

\section{Introduction}

Television in Europe has traditionally been marked by strong public service institutions. Although the television companies in various European countries may differ from each other in organizational form and in the details of their policies, the idea common to the companies has been to avoid commercial financing (Ang 1991, Wieten et al. 2000). This is in contrast to the US, where the organization of broadcasting was commercial from the very start (Barnouw 1975/1982). These differences, which have been at hand since the end of the Second World War, however, have become less apparent from the 1980s and onwards, when the rapid spread of commercial television brought with it dramatic increases in the quantities of television programmes on offer for viewing audiences in Europe. The fact that there was a quantitative increase in programme time available also brought with it a change in the premises under which television is produced. This change can partly be attributed to technological developments in production, but it can also be attributed to the fact that programming has had to adjust to the commercial environment.

One such consequence for programme content has been the increased intermingling of components from entertainment and factual television, leading to new genre mixes, and new programme formats (several reality formats, for example). Thus, there is an increased presence of documentary forms within fictional and entertainment productions, as well as an increased emphasis on narrative forms from entertainment television in factual television.

Another and more evolving consequence, however, has been the changes in the principles of how the textual progression in programmes is constructed, especially in non-fictional television genres. One might argue that the specificity of televisual text construction 
is tied closely to live television formats, as live broadcasting is a founding characteristic of television as a medium (Heat \& Skirrow 1977, Feuer 1983). Live television is also a form of television that transgresses both entertainment and factual genres, in contrast to fictional genres specific to television, such as the sit-com (cf. Feuer 1987/1990).

Against the background of empirical research on television production in Sweden, and with examples taken from both entertainment and factual live television productions, this article intends to discuss the transformation of textual structures in live non-fictional television programming, as related to production features. The main objective is to understand how textual forms in entertainment and factual television relate, and I will suggest a model for an analysis that relates the textual premises under which television programmes are being produced to the narrative and generic elements that are activated in the production practices as well as to the textual features of the television programme as it is broadcast. This model should explain why certain texts take on a specific form, as this form will inevitably have consequences for which readings will be privileged in the interpretative work of audience reception.

My main examples are selected from four different kinds of live productions. They exemplify a spectrum of different genres, or formats, as these are generally perceived. Although we might think of them as belonging to different genres along axes of factual and entertainment television, all are characterized by the quality of liveness.

My first example is the Swedish lottery game show Bingolotto (for the analysis of which the model was developed; cf. Bolin \& Forsman 2002), broadcast in Sweden since 1991 on Saturday evenings (since spring 2004 on Sundays) on the 'hybrid channel' TV4 (cf. Syvertsen 1996). ${ }^{1}$ Bingolotto then exemplifies national, entertainment television, produced by an independent production company in a commercial setting. My second example is a trans-national entertainment production organized by public service companies, aimed at an international audience through public service broadcasters (although broadcast also via commercial channels) and ultimately organized by the European Broadcasting Union (EBU): the Eurovision Song Contest. I will relate mostly to the production of the show in Tallinn in May 2002. My third example is the prime time edition (30 minutes) of the news broadcast Rapport from a public service channel (SVT), and my fourth example is the Swedish election night coverage (Valvakan 2002) in connection with the parliamentary elections in September 2002, produced as an in-house production by TV4, thus making this also an example from a commercial setting.

I have first-hand observational knowledge of all of these programme examples, although to various extents and depths. I have personally been present in the 'studio' at all occasions (in the case of Bingolotto on several, and in the case of ESC 2002 also at dress rehearsals), and have taken part of, and/or had access to, observations and discussions during the planning and preparation of all productions. ${ }^{2}$ I have also had access to, albeit to different degrees, interviews and conversations with production staff. And I naturally have had access to the television text on video.

My analysis will be at the level of the programme texts, although I also acknowledge that all the examples also are produced as series. I will do this by analysing live studio productions along three dimensions. ${ }^{3}$ The first dimension concerns the relation between factual and entertainment forms: To what extent is it possible to analyse textual forms in entertainment and factual programmes along the same lines? What similarities are there in the production process, and how do any similarities affect the visuals? The second dimension relates to national and international television production. Is there an approximation of trans-national textual forms of television? And, if so, what are its 
distinctive features? The third dimension concerns the relation between public service and commercial television. As the re-regulation of European broadcasting has led to public service and commercial companies competing (or at least co-existing) with each other, I wish to analyse the similarities and differences between commercial and public service broadcasters. What are the main differences - if any - in the ways in which programmes are produced within the two systems?

I will start this discussion by pointing out the main changes in the field of television broadcasting in Europe, leading to the phase that John Ellis (2000) has termed 'the era of plenty'. I will do this with a special focus on how these changes have affected production practices (and with a special focus on those changes in production habits that have been of importance for the textual features of television programmes). I will then describe my programme examples, and specify my questions in relation to these. The main discussion of the textual construction of liveness is organized around three parts: production premises, textual segmentation and textual elements. I will summarize this discussion by describing the segmentation of each of my examples, before I make some conclusive statements concerning the dimensions factual/fictional, national/international and public service/commercial.

\section{The Era of Plenty: Changes in European TV Production}

As indicated above, the public service institutions have stood strong in many Northern European countries. Although the trend in all European countries has been similar, the Nordic countries were among the last to open their broadcasting systems to commercial competitors in the 1980s (Brants \& De Bens 2000 p. 21). The re-regulation surrounding the public service monopolies has naturally changed the structures of media organizations (cf. Curran 2000) and has affected output structures both quantitatively and qualitatively (cf. Asp 2004 for a Swedish example).

Quantitatively the changes have led to the rise of more television channels, more programmes, new genres and formats. More organizations and individuals have also become involved in television production, and there has been an increased change from in-house production (which was the dominant production form within the public service enterprises) to independent production companies serving both commercial and public service channels. At the time of de-monopolization of public service, a space was opened up in the field of television production for people who had not previously had the chance to produce television (i.e. amateurs and civil society organizations, as well as commercial entrepreneurs). This historical unfolding seems to have occurred in much the same way in several European countries, such as in Sweden (cf. Bolin \& Forsman 2002), Norway (cf. Bakøy \& Syvertsen 2001, Dahl \& Høyer 2003), Denmark (cf. Skovmand 1992), as well as in the UK, although in the UK at an earlier point in time (cf. Robins \& Cornford 1992, Paterson 2001). This may partly explain the rise of new genre mixes. As I will show in greater detail below, people with little or no experience of television production are not restrained by generic thinking in the same way as are those who have long been working in the industry.

Partly as a result of these quantitative changes, and partly resulting from more general societal (economic, social, ideological) changes (cf. Ellis 2000 p. 62), there have also been qualitative changes in the television systems. The new 'demand-led production' (Ellis 2000) has meant that production has taken on new organizational forms. It has, for example, led to serialization and industrialized production, in which several episodes of 
entertainment shows of different kinds are produced each day. ${ }^{4}$ In this 'era of plenty', as John Ellis (2000) terms it, production becomes increasingly separated from distribution. Production enterprises have mushroomed over the past fifteen years, and television channels have restricted themselves to buying productions from external production companies, allowing them to concentrate on their functions as distributors. As a consequence of commercial financing, certain formats and programmes also tend to be privileged, e.g. those that have a young audience (and the aesthetics that can be attached to such programmes). There has also been an increased emphasis on niche audiences. The wellspread cliché that commercial media strive to maximize the size of the audience is far from true today. It is more important and cost-effective to reach the right audience without attracting unproductive viewers who do not fit into the niche segment, and whom the advertisers do not want to pay for - that part of the audience that is termed 'waste' in the advertising jargon (Bolin 2002, p. 192f). Consequently, formats have become increasingly important for the television channels. This has led, to a much higher degree than before, to the development of a separate market in which formats are bought and sold as commodities. Furthermore, as more parties have become involved in the production process, and as they have various and sometimes contradictory aims for their productions, there often arise conflicts of values (economic certainly, but also social, political and cultural), and these also have effects on the television text (cf. Bolin 2004).

\section{Codes of Liveness}

In Stuart Hall's (1973) famous 'encoding-decoding' model, one of the contextual components for the moment of production (as well as the moment of reception), besides 'technical infrastructure' and 'relations of production', is 'frameworks of knowledge'. These frameworks are naturally of several kinds: knowledge of how to run technical equipment, of how to administrate economics, of how to write scripts, etc. One such framework of knowledge is the genre system. The genre level could be said to be one of five textual levels of analysis, where the most textually close is that of the segment. Then follow the level of the programme, the schedule, the genre, and lastly the level of the 'megatext', comprising the totality of the television output (Ytreberg 1999 pp. 26f). The concept of genre in media production studies often points to standardized production practices. However, it also refers to standardized narrative codes to be found in the text, and to certain dominant ways of interpreting texts. In all entertainment and factual productions there are certain standardized expressive features and repetitive methods in the production - of talk shows, news broadcasts, game shows, current affairs programmmes, etc. The literature on genres in television is substantial, and I will not relate to the entire body of works within that area (for examples, see Altman 1999, Cawelti 1976, Fiske 1987, Lacey 2000). My argument rests on the fact that the genre system is prescriptive, and can be seen as a code that is at work in both production and reception (Berger 1992). And the one feature I will forefront here is the code of 'liveness'. News productions as well as many entertainment programmes have liveness as one of their significant features, and it has been pointed out that the production practices for the two formats are quite similar (Hirsch 1977 as quoted in Ytreberg 1999 p. 12). However, there is also a tremendous difference between the code for liveness in a news broadcast and that for liveness in a game show (Bourdon 2000).

Liveness as a televisual code does not presuppose that the programme is actually broadcast live. Of course many productions are broadcast live, but quite a few are 'live 
on tape' productions, which means that they are recorded and broadcast as if they were live. This means that their narrative construction is linear, causal and has a clear direction. Events happen in real time (they take as long to represent as they take to happen), and there are no ellipses or other techniques to overcome linear clock time. Although several camera angles may be involved, obviously shot from different camera positions, the events they cover unfold in real time. There is a direct visual and aural address: the host/news anchor talks as if he or she were talking to me as a viewer right now, and the visuals are presented as things are happening at this very moment. Interviews are not made to look edited (although they often are), games take as long to play as they do in un-mediated contexts, etc. In short, the editing techniques are carried out so as to result in seamless texts that unfold in front of the eyes of the viewers. As Jérôme Bourdon (2000) has pointed out, the notion of belief is central to the live quality, in the sense that there is a willing 'suspension of disbelief' on the part of the viewer. Furthermore, also productions that are live broadcasts in the sense that they broadcast events as they happen (the typical example being the sports event/broadcast) often have non-live components. A news broadcast may have a taped interview in the middle of a news feature. Sports broadcasts have replays of important moments in a game, which paradoxically can enhance the liveness quality. There are pre-recorded elements in game shows, such as presentation clips of prizes. And sometimes, in order to fit the overall programming schedule, interviews with politicians on the night of the election that actually could have been broadcast live are not, in order to fit better into the overall flow of the programme. In the election coverage on TV4 as well as on SVT, reports and interviews from the different party headquarters were broadcast with delay, but made to look like live broadcasts, which was also commented on in the press the day after the broadcast (cf. Björkman 2002). They were presented as if they were live, and we usually think of all these programmes as live transmissions. ${ }^{5}$ They are thus 'plausibly live', a technique initiated by NBC during the 1990 Olympic Games in Sydney, when the company, due to the time difference between Australia and the US, postponed the broadcasts for the US audiences, making them seem as if they were live in the morning (Reimer 2002, pp. $231 \mathrm{ff}$ ). This delay made it possible to adjust the broadcast to what supposedly would attract the US audience, with a special focus on US athletes.

Live television, then, is very seldom entirely live. Live shows are a mixture of pre-recorded parts, live studio footage, and pre-prepared computer graphics and video effects. Out of the 180 minutes scheduled for the ESC 2002, only 130 were live transmission. The rest consisted of pre-recorded material (Forsman 2002 p. 72). This has always been true for news productions, which have mixed live reports from the news anchor with taped reports from far-away places. But it can be argued that this has also become more common in entertainment productions. This is especially valid for game shows. The lottery draws on Bingolotto are made beforehand and are simulated live, but made to look as if they were drawn live each Saturday night, since Swedish legislation prohibits live lottery draws. This is a well-known fact that seems to have had little influence on the audience's willingness to accept the programme as a live broadcast and to interpret the situation as one in which lottery numbers are drawn the moment the number is revealed on the television screen (Bolin \& Forsman 2002).

When discussing live television, thus, it is valuable to distinguish between live broadcasts with moments of pre-recorded material and 'live on tape', a distinction Bourdon (2000 p. 538) has termed as being between 'fully live' and 'continuity television'. However, the textual quality of liveness is central to both kinds of programmes, although the 
practices and techniques for constructing that liveness differ (cf. Forsman 2002 p. 70f). This textual quality is composed by a combination of characteristics. Perhaps most fundamentally, the textual quality of liveness is constructed in 'the media paratext', as Gérard Genette (1987/1997 quoted from Bourdon 2000 p. 535) refers to it. This paratext consists of all surrounding texts that generically place the format in the live category: the newspaper tableaux over television programmes, the title (e.g., Saturday Night Live), trailers, etc. The most obvious of these paratexts is probably when the channel announcer cues the program: 'And now, directly over to the studio in Gothenburg, and Bingolotto'.

There are, however, other varieties of liveness. In between what Bourdon calls fully live and continuity television can be found what could possibly be called 'delayed live'. Delayed live can be exemplified by sports events that are broadcast with a 30-second delay. These broadcasts are not edited, whereas live on tape may be. They are rather imprinted by simultaneous live editing, but with a short delay in transmission.

It is possible to identify at least four characteristics of the live code in my examples, and they can also - each of course to varying degrees - be applied to other productions/ texts as well (cf. Bolin \& Forsman 2002 p. 162f). The first of these is simultaneous (live) editing. This naturally follows from the fact that if you broadcast as things happen, you have to edit in accordance with how you expect things to happen, or - as is more common - how you have planned things to happen. This is, of course, not necessary with live on tape, where the opportunities for post-editing are greater. The technical jargon for live editing among media production people, at least in Sweden, is to 'play hockey', indicating that the camera and the editing have to follow the events as they occur, similar to how the camera editing has to follow the movements of the players in an ice hockey game. In the production of Bingolotto, the staff used the phrase 'follow Leif', which meant that the camera work had to concentrate on following the sometimes unpredictable movements of the programme host Leif Olsson around the studio. (One reason for this unpredictability was that Olsson, quite an eccentric personality, never rehearsed before going on air.) One consequence of this practice was that the lighting in the studio had to be of a general kind. After 1999, when Olsson was replaced by a younger, and more US-inspired programme host, the practice of rehearsals was introduced. As the new host rehearsed before the programme went on air, and also had cues in the floor for special movements, the possibilities for lighting arrangements expanded, which set its clear mark on the text. Rehearsals are of course also of utmost importance for a major media event such as the ESC, where each moment in the programme - except for the repeat of the performance of the winning contribution, which can obviously not be rehearsed - is rehearsed in minute detail.

Second, live studio programming is most often (although not exclusively) produced with multi-camera settings. ${ }^{6}$ To be able to work with a variety of camera angles and movements, you naturally need to have more than one camera working. Often there are at least three floor cameras, several fixed cameras, at least one crane, and a steady-cam. The general rule of thumb is that, the bigger the event, the more cameras. Thus, for the production of Bingolotto, there were most often seven cameras (including one crane and one steady-cam). This was similar to the production of Valvakan. For ESC, being a much bigger event (and a bigger studio - the sports arena Saku Suurhall), the number of cameras was eighteen, including one steady-cam, two cranes, and 6-8 fixed cameras. The functions of all these cameras of course vary with the kind of production, but generally each camera has the function of performing certain angles and standard visuals. Entertainment productions such as Bingolotto (especially the music segments), and in 
the performances in ESC, steady-cams and cranes are used to a much higher degree than in a factual production such as Valvakan. With the use of cranes and a steady-cam, it is possible to create vivid movement in the visual expression, even though the visual object to be represented is non-moving. A power ballad like the one performed by Romania in Tallinn 2002, where the two singers were standing fixed to their positions on the stage, which they themselves said was intended to express intense emotions, could be made 'moving' only through the extensive use of the two cranes and the steady-cam. The non-movement of the singers trying to touch and move the hearts of the European tele-voters became vivid through the movements in the camera work. But also in uptempo songs, the vividness has to be produced, and the visual techniques for this have long been elaborated in the music video formats.

As a third feature, live studio productions are often characterized by the use of multistage settings in the studio. These are of three major kinds: the stage for the host, the artist's stage (may be exchanged for having a guest stage in factual programmes such as Valvakan 2002), and the stage for the studio audience.

The stage for the programme host and his or her guests is often placed centrally in the studio, opposite to and facing the audience stage. The host's stage can be in the form of the news anchor's desk, which can be used for interviews and direct address to the camera/audience. News broadcasts are exceptional in this respect in that they do not have studio audiences (and do not pretend to have them by using 'canned laughter' or other special effects). This consequently makes the camera work static, and accordingly also the textual expression. This 'staticness' then is actually one of the main liveness codes for news, indicating seriousness and authority. However, it can also be the desk of the talk show host, as in, for example, Late Night with David Letterman (or its Swedish counterpart Sen kväll med Luuk).

Another stage is designed for the performing artists or guests. This is of course the most important stage in the case of an event such as ESC. However, this stage is usually also designed to change in shape and colour scheme depending on the performing artist. This stage can, in factual programmes, be intended for special studio guests (rather than for performing artists), like the continuously changing guests commentators seated at a podium in front of the (young) audience in Valvakan.

A third stage is dedicated to the studio audience. The studio audience has become an increasingly important component in constructing liveness, especially in connection with musical performances, but also with game and talk shows. In ESC 2002, the dedicated fans in the audience were seated closest to the stage, surrounding its cat-walk, allowing them to act as fans, waving flags, hands raised in the air, dancing along with the songs. In Bingolotto, the audience is the representative with whom the viewers at home can identify, extending the studio room into the living room. In the case of Valvakan, it was obvious when talking to the producer beforehand that the students they had invited to be in the audience, to make up the backdrop for the interviews and political commentaries, would represent the politically concerned young voters whom TV4 wanted to reach, as they frankly stated that this was a group that was hard to attract to current affairs programmes (but important to the advertisers). The studio audience then has several functions: to form a visual background to other events (interviews, lottery draws, etc.), to create atmosphere for performing artists (playing live in front of a host and a couple of camera operators might not feel too inspiring), and to function as a point of identification for the viewers at home. These functions are of course not mutually exclusive, and in each broadcast all functions are more or less active. 
The multi-stage setting is often, although far from always, combined with multiple hosts - most often two (and then preferably one of each sex as in the Eurovision Song Contest and in Valvakan 2002). The programme host is of course of utmost importance for entertainment shows, and the equivalent - the news anchor - has become increasingly important as an identification mark for news broadcasts. Thus, many shows are entirely built around the host, indicated by the fact that the show name includes the host's name (the earlier mentioned Letterman, Rikki Lake Show, Oprah Winfrey Show, Hylands hörna, etc.). The programme host is the person who connects all of the show's parts or, if it is a news broadcast, the person who connects the various news items, which in themselves have little or nothing in common, thus forming a coherent narrative.

If one host brings the parts of a programme together, having a pair of hosts allows more flexible use of the various stages during a live broadcast, as the cameras then have better opportunities to switch between hosts/stages. The host, then, has a 'relay' function in the programme. This naturally also makes it easier to re-arrange the artist's stage between acts, allowing each performing artist to have his/her own, individually designed visual expression. This is of fundamental importance for live shows such as the ESC, or any other large show. Such live events can be said to have grown into a separate sub-genre from the late 1990s and onwards. The typical event is a fund-raising charity event. In shows with single hosts, there is often one person on the set, sometimes several, who act as talking partners to the host. One example is the leader of the orchestra in Late Night with David Letterman. This model was picked up in Bingolotto, where the host, in the same way as Letterman does, starts every show with small talk with the leader of the house orchestra. However, one of the cameramen, or the producer, could also function as the verbal sparring partner for the host.

Duo hosts have their equivalent in news productions in the duo anchorpersons, likewise preferably one of each sex. The functional aspect of this is of course the same as in entertainment productions: to allow for flexibility. Having two hosts instead of one can naturally be explained by the fact that it is more natural to have a dialogue between two persons chatting away, than to have a single person addressing an audience. This has long been a standard feature of sports broadcasts, where commentators are usually a journalist and an ex-athlete from the relevant sport.

The host is also a key component in the construction of liveness. The prime instrument in creating liveness that the host has at his or her disposal is direct address into the camera. Direct address indicates that the host is talking to the individual audience member, and that he or she is doing so in the present. The programme host has a specific authority, based on rhetorical techniques, in defining the interaction - both in the studio and with the viewer (Ytreberg 1999 pp. 72ff, Morse 1986). However, the host can also deliver pre-planned and rehearsed mistakes (stumbles, Freudian slips, etc.), contributing to the sense that what is happening is not fake, but real, i.e. not rehearsed, and thus live. A technique used in Bingolotto after the change of host (and the introduction of rehearsals) was for the producer to arrange surprises for the host, things not rehearsed or agreed on beforehand, as this made the surprised face of the host more authentic. And what might look to the viewing audience as a spontaneous flirtation with the camera during a song performance in the ESC revealed to be entirely rehearsed to the researcher present during a few dress rehearsals (Forsman 2002 p. 76). And the spontaneous and ethnically French gesture with the hand to the head delivered by the female head of the ESC voting jury, seemingly a gesture of the moment, does not have the same impact on this author after having seen it performed in both dress rehearsals and the live broad- 
cast as it probably has on those millions of television viewers who have not had such privileged access to both performances.

In conclusion, then, it is possible to summarize the codes of liveness, as they are performed in many, although far from all, live studio productions. Codes of liveness are thus displayed in simultaneous live editing, multi-camera, multi-stage and multi-host settings. However, these kinds of props, which are the cornerstones of live television programming, would be nothing if they were not combined with and related to narrative structures, the patterns that structure time within television discourse.

\section{Spatial and Temporal Construction of Liveness}

The texts in television entertainment and factual programming are constructed in relation to two kinds of textual premises: space and time. The first, spatial dimension of live television production concerns what kind of studio space or other recording facilities you have access to, for example, what out-of-studio places can be used in the narrative. In the spatial dimension can also be included those kinds of things you fill the space on the screen with: props, people, etc. The second important premise for live productions is the extent to which the producers can structure time. One could of course say that all television production deals with the administration of time, but there are certain temporal features that are highlighted in live productions: scheduled time, transmission time, programme time, commercial time, etc. When it comes to programme time, however, segmentation is important for how the television text is constructed into a specific form.

\section{Spatial Textual Premises}

The spatial dimension can be sub-divided into studio space and out-of-studio places. Access to places outside the studio for live productions involves, for example, production teams with OB equipment, making it possible to link together various places, as was done in Valvakan, where reports from the seven party headquarters were linked together in the broadcast via (seven) OB buses that could transmit live material (although the segments sometimes were delayed in order to fit into the broadcast as a whole). This is of course also common in news production, where foreign correspondents are interviewed by the news anchor. On an even more complicated level, co-operations between several national broadcasting companies make it possible to interconnect many European cities, as is done in the ESC voting procedure (cf. Åker 2002). The importance of these outof-studio places for the textual address, and the weight put on including these places, can be exemplified by the fact that Swedish Television (SVT) - the competitor that TV4 was programming head to head with Valvakan - made an offer to the involved political parties to arrange for the decoration and setting of the localities where they would wait for the election results, in order to get a competitive advantage over TV4. (The political parties, however, did not accept the offer.)

Of even more fundamental importance for the television text in most live television formats (with the obvious exception of broadcasts that are entirely based on out-ofstudio places, such as sports broadcasts) is the studio setting. When Bingolotto started their broadcasts, the studio was a lunch diner that was used in the evenings as a studio. Obviously, the use of cranes was not possible at that time, and the technical facilities for lighting were definitely not optimal compared to a fully equipped in-house studio. There is, therefore, a striking difference between the programme text from those early 
days and the programme text today, when the studio is located in a specially restored factory building. On the one hand, the studio room has to be constructed to facilitate camera movement: There has to be clear space on the floor for the floor cameras, height enough for the cranes, and space enough on the artist's stage for the steady-cam. But the studio also has to be constructed as a meaningful communicative space that can express the programme's profile and communicative intentionality. Thus, every news programme has its own specific studio setting, with specific colour schemes and visual props. In serialized productions such as Bingolotto, the studio setting is changed for every new season, although the artist's stage is changed every week to fit the performing artist. This is of course also the case with the ESC, where every new production seems to try to be more spectacularly produced than last year's, due to the internal competition between the broadcasting institutions. However, the two productions of 2002 and 2003 were produced by the same team - a combination of staff from Swedish SVT, Finnish YLE, and Estonian ETV and Latvian LTV, respectively. Not surprisingly some of the textual features of the 2002 version were repeated in Riga 2003.

For every television programme there are, besides the studio setting, several components that are of importance for construction of the text. Each segment is, first, constructed through a combination of various camera positions. Through standardized camera positions, the space on the television screen is constructed, and everyone who has been in a studio at a recording session knows that there is a difference between how you perceive the studio space on- and off-screen. A closer look at any programme within most of the live formats, then, reveals that the programme has certain standard camera positions that are repeated over and over, and combined in various ways: long shots, medium shots, close-ups and extreme close-ups. The use of different cameras naturally allows various movements, where the cranes and the steady-cams are used for making vivid movements, while the floor cameras usually pan or tilt slowly, and the steady-cam often has specific patterns for its movements, not least because it is sometimes - as in the ESC 2002 - operated by two people who have to synchronize their movements when revolving around artists, etc.

Second, the cameras are directed towards any of the textual elements that make up the studio setting: programme host, audience, artists, house orchestra (and their various members), guests, but also presentations clips and digital and other graphics.

\section{Temporal Textual Premises}

The temporal dimension can be sub-divided into different temporal categories: schedule time, transmission time, programme time, advertising time. The scheduled time of a programme such as Bingolotto is that time that is announced in the television schedules, for example starting $19^{00}$, with a break for a mini-programme $19^{35}$, starting again $19^{40}$, etc., and ending with the beginning of a new programme at $21^{00}$. When looking at a production such as Bingolotto, which has run for more than a decade, it is obvious that the schedule time has become more important for the broadcasters, as Bingolotto is currently an integrated part of TV4's overall strategy for Saturday evening (cf. Søndergaard 1994, Syvertsen 1997 pp. 119ff, Ytreberg 1999 pp. 115ff). The Saturday evening schedule has become a whole, in which certain slots are to be filled by certain formats (Bolin \& Forsman 2002 pp. 182f). Furthermore, out of the 120 minutes of the scheduled time between 19 and 21, the total programme time, i.e. the time that consists of the transmission from the studio in Gothenburg, usually varies between 95-100 minutes, leaving at least 
20 minutes for commercials, trailers and mini-programmes. Programme time, then, is usually shorter than scheduled time. However, transmission time, is always longer than scheduled time. Although according to the schedules in Sweden the ESC started at $21^{00}$, the actual transmission started at $20^{50}$, in order for the European broadcasting companies to make technical adjustments, etc. (Forsman 2002 p. 71). Advertising time, of course, also varies, as the economic logic of supply and demand entails that the broadcasting channel has sometimes been successful in selling all available advertising time, and sometimes not (Bolin \& Forsman 2002 p. 183).

The combination of all these different types of time contributes to the totality of the programme (and, of course, also varies between viewers' viewing time). This totality can, for the same scheduled event, differ between different broadcasters, which becomes obvious when we look at an international media event such as the ESC. As SVT does not have commercials, the Swedish viewers could see the duet between the programme hosts Annely Peebo and Marko Matvere in the first commercial break of three minutes, and the slightly more than seven-minute-long 'Interval act', where dancers and the ETV children's choir performed an act representing the birth of the Estonian nation (Forsman 2002 p. 72). In contrast to the Swedish viewers, the Estonian viewers were served commercials during these breaks (as were viewers in other countries where the programme was broadcast on channels with commercials).

All these textual premises affect the narrative possibilities in the production, and lead to the development of textual units such as blocks and segments, which are in turn constructed out of standardized camera positions, and visual and aural elements (props). All of which are building blocks in the textual construction, and ultimately have a bearing on how the text is temporally structured in textual segmentation.

\section{Textual Segmentation}

In his influential book Visible fictions, John Ellis introduced the concept of segment - 'small sequential unities of images and sounds whose maximum duration seems to be about five minutes' (Ellis 1992 p. 112). However, there are also additional unities that can be theorized in television narration: programmes, schedules, etc. (cf. Ytreberg 1999 p. 26f). Another unit that can be suggested for some, although far from all, programmes, is that of the block. It could be argued that, in commercial television, you do not work with programmes, but instead with blocks. A block could be described as the time between two commercials, and it often contains several segments. Different broadcasting companies in different countries have, according to praxis or depending on the national legislation for commercials, different periodizations between commercials. Some broadcasters can, for example, make breaks in programmes for commercials. Other's - like Swedish TV4 until recently - cannot interrupt programmes, but instead develop sophisticated techniques to circumvent those regulations, by scheduling short two-minute programmes that interrupt longer shows, such as Bingolotto, placing the commercials before and after those two minutes and then continuing with the game show. The block structure is more pronounced in Bingolotto and Valvakan than in the ESC, not least because ESC is arranged by public broadcasters, and because the format of the show was developed in 1956 - long before the advent of commercial television in most of the countries involved.

The block structure could be argued to be one of the founding premises of commercial television production. And because there has been an increase in independent production 
enterprises serving both commercial and public service channels, this also affects public service programming. One possible thesis is that because formats are bought and sold between countries with both commercial and (non-commercial) public service companies, one could expect the block structure to become more prominent in the future.

Undeniably game shows, such as Bingolotto, Jeopardy, etc., often have this block structure. Blocks often have some core element at their centre. For Bingolotto, the natural block structure is centred on the three bingo games. For other game shows, it can be centred on each round in the game, or a new block can start with the exchange of players, such as in Who wants to be a millionaire? Or, as is often the case in talk shows such as Late Night with David Letterman and Rikki Lake Show, it can be centred on the introduction of a new guest. The block structure, where each block contains several segments in combination, gives the show a repetitive character.

This repetitiveness is further emphasized through the internal structure, that is, the narrative motor, of the segments. As each segment has its own internal structure, each block often consists of a number of different segments, which are repeated, although not always in the same order. Each block of Bingolotto, for example, usually contains five kinds of segments (some of which are repeated within the framework of each block): bingo games, music performances, phone-ins, lottery draws and 'lucky numbers' (i.e. lottery draws on a wheel).

The sequential structure of a bingo game segment is naturally driven by the unfolding of the bingo game. 'Narrative closure' is reached when enough people have received bingo, which is announced verbally by the programme host, and shown visually through a computer animation of the sign 'Bingo!' displayed over the television screen.

Music segments start by the announcement of the artist by the programme host. Then follows the musical performance by the artist, with a musical intro, verse, refrain, etc. The segment reaches its closure when the host thanks the artist. This segment is then structured by the musical conventions typical for the music genre in question, thus an auditory drive rather than a visual one (cf. Lacey 2000 pp 43f).

Phone-ins are structured by the conventions guiding speech communication, and reach closure when the host thanks the person phoning in to the studio.

Lottery draws have an even simpler progression, where the numbers circulating on the screen slowly stop one by one until all have stopped and the winning number is displayed. This segment is often repeated, so that there are, for example, four combinations of numbers drawn in a row.

Lucky numbers typically starts by the turning of a wheel, and ends with a person present in the studio winning (or not winning).

The combination of these segments in Bingolotto can vary, both between blocks and between programs, but all blocks have at least one of these segments.

In a similar way, Valvakan is constructed through the combination of segments, where the duo hosts Bengt Magnusson (famous news personality and incidentally also the person hosting Who wants to be a millionaire? in Sweden) and Malou von Sivers (an experienced programme host who has worked a great deal with morning television) take turns at their respective stage: Magnusson taking care of the statistics and the academic and journalistic commentators, Professor of Political Science Peter Esaiasson (as reported by the producer chosen because he is young and handsome), and political journalist Lena Smedsaas; and von Sivers interviewing guests in a sofa setting, where the guests were placed in front of, and with their backs to, the youthful audience. 


\section{Blocks, Segments and Textual Elements}

It is obvious that the block/segment model is better suited to the examples of news, election nights and live entertainment, and somewhat less appropriate to the ESC. If one compares the general structures of the four kinds of programmes, one finds that there are between five to seven kinds of segments within each block. Some of these segments are repeated several times in a row within each block, others appear only once.

Each block of Bingolotto contains five kinds of segments (and the first block an additional presentation segment): bingo segments, music segments (artists performing), phone-ins, lottery draws and 'lucky numbers'. And each individual segment is built up of a range of standardized camera positions and movements, as well as of textual elements such as the host, studio props, audience, studio orchestra, artists, graphics, etc. Some of these segments occur several times within each block. There is only one bingo segment, and usually only one music segment (naturally only one presentation segment), but there are several phone-ins, lottery draws and lucky numbers. Especially the phone-ins are often four in a row (sometimes only two), and this is also the case for lottery draws. There are sometimes several lucky numbers, but they are seldom combined in rows.

If we apply this model to the other examples, we can see that each block of Valvakan 2002 contains five kinds of segments (and the first block an additional presentation segment). There are presentations of statistics, expert evaluations of the events unfolding made by the male host together with a political scientist and a journalist, expert evaluations made by the female host and politicians and other commentators, reports from party headquarters (stand-up's), and there are edited, pre-recorded features. Just as in Bingolotto, the segments are composed of a range of standardized camera positions and movements, as well as of textual elements such as the two hosts, studio props, audience, guests (politicians, researchers, journalists), graphics, etc. The first of these segments runs for 31 minutes and 50 seconds, which is followed by 4 minutes and 30 seconds of (10) commercials, and 30 seconds of trailers. Then block number two starts. All in all, the programme text, including commercials and a short break for news (containing the same footage from the election night coverage supposedly transmitted live), lasts for three hours, 52 minutes, and 18 seconds.

Just as in Bingolotto, the block starts with an intro with graphics, then an establishing shot from the crane from the back and above. These are not segments in themselves, but relay functions, or shifters between the segments. The segments in Valvakan 2002 are not as varied as in Bingolotto, as all of them are structured linguistically, following the format of speech communication. The motor of the segment, then, is modelled on the interview structure, and the segments end by a relay from the interviewing reporter over to the studio, or over to another reporter, relayed by the short 'relay shot' via the studio. In this way, the various segments are brought 'into an interactively structured relationship [of] metadiscursive exchanges in and between spatially dispersed locations' (Marriott 2000 p. 136). The only more narratively complex segments are those pre-recorded and edited features from different election districts around Sweden (interviews with election functionaries, etc.).

The segments in Valvakan are only structured in rows with regard to reports from party headquarters, which are sometimes broadcast alone, sometimes in pairs (relayed by the male host Magnusson).

However, as there are two hosts for the show, the relay function of the host can be varied in more ways than is the case in a single-host setting such as Bingolotto. The host 
Bengt Magnusson is responsible for the statistics and for the two experts (the researcher and the journalist), as well as the arriving party leaders after the result has been confirmed. Malou von Sivers is assigned to the (other) politicians and the other experts and guests in the studio. This work division is upheld throughout the program.

Undoubtedly, the similarity between the different segments, caused by the base in the interview or in the reporting of statistics, follows from the fact that the unfolding of events is harder to predict than in an entertainment show such as Bingolotto, or a mega-event such as the Eurovision Song Contest. This means that sometimes the segments do not reach full narrative closure, as the producer shifts too quickly to other segments/studio locations, a phenomenon that is quite common in election night coverage and similar productions in which producers do not have total control over how events are developing (cf. Marriott 2000 p. 141).

In many ways a news broadcast is similar to the narrative structure of a programme such as Valvakan. However, there are basically only four kinds of segments: the presentation segment with the headlines, telegrams, news features, and a weather report. The segments in news broadcasts differ primarily according to content rather than form: sports news does not differ in form from domestic news, or economic news. The narrative motor in news is also mostly structured around the discourse of speech communication: either the interview or the telegram. News features, however, are sometimes driven by the visuals.

If we, however, look at the Eurovision Song Contest, we can see that the segmentation is somewhat different. Here we find five segments, or we might also count the 'Interval act' in the middle of the show, where a pre-recorded feature described the rise of the Estonian nation in history (while those watching on commercial channels or public service channels with commercials were served advertising clips). Aside from this segment, there were music segments (songs performed), the reporting of votes from the competing countries, fairy tales in-between the music segments, reports from European cities on the festivities around the broadcast, and finally, reports from the so-called Green room, where artists wait for the results of the tele-voting procedure.

As can be seen, the Eurovision Song Contest, first, has a more varied set of segments than do the other examples. This can be explained by the fact that not all segments are driven by the interview structure, as in Valvakan 2002, but some by the musical structure, in the same way as the musical segments in Bingolotto. The fairy tales, on the other hand, derive their internal narrative structure from well-known fairy tales such as Little Red Riding Hood, The Three Bears, Goldilocks, etc., although their endings deviate, as they all are aimed at displaying the advantages of Estonia and promoting it as a nation (Bolin 2006).

As the Eurovision Song Contest is broadcast in at least two different versions - one with and one without commercials - this affects the block structure of the program. In those countries that have commercials, the show is divided into blocks, whereas in Sweden and other countries without commercial breaks, the programme is uninterrupted and hence consists of only one block.

But it is quite evident that the Eurovision Song Contest is less well suited to the textual structure described in the analysis. The main reason is no doubt its older history, and the fact that it is a product of textual forms privileged by the public service monopoly situation in 1950s Europe. 


\section{Conclusion}

At the beginning of the article, I posed three questions, concerning three dimensions, to the analytic examples. First, I wished to analyse the relations between factual and fictional programmes to see whether it would be possible to adopt the same analytical strategy to analysing these genres. Second, I wished to analyse the relation between national and international productions, to see whether and to what extent one could see similarities in the production practices and hence in the programme text. Third, I wished to analyse the possible differences and similarities between public service and commercial productions. So, what more general conclusions, in relation to these questions, can we draw from these descriptions? What are the consequences of production practices, the relations of production, for the development of new genres and formats?

There are at least two kinds of features related to this that make their mark on contemporary live broadcasts. On the one hand, television texts have become increasingly additive in their structure in order to adjust to the segmentation between the commercial breaks. On the other hand, the additive structure with interruptions for commercials also means that each segment has to build its own 'micro-narrative'. This gives the segments a repetitive character, which ultimately leads to a circular temporal structure of the programming.

This structure is not fundamentally different as compared to entertainment and factual genres. Although not all programmes can be divided into blocks, all have separate segments that give the programmes a circular, repetitive and additive character, which, in turn, gives the textual structure or narrative a flat character without the overarching peaks and resolutions of, for example, feature films. As mentioned in the beginning of the present article, news has always had this form, with short news items added one after one another into a master narrative that, in terms of content and with minor internal variations, covers domestic news, international news, sports and a weather report. This may also be the explanation for why news seems to have come out the least transformed after the re-regulation processes. Regarding textual form (although perhaps not content), most other genres have approximated the flat and additive textual form of news rather than vice versa. The exception is, as has been indicated above, the Eurovision Song Contest, which has not had to adjust to this form for half a century.

This also means that the over-arching structure of the Eurovision Song Contest differs from the other examples. However, it might be possible to argue that, at the level of individual segments, there has been an adjustment. So, at the level of the programme, there is a difference between the national and international examples, but not necessarily at the level of individual segments. This could be because large-scale international media events, to an increasing extent, are being produced by production teams composed of staff from several national television companies, many of whom have worked within commercial television production. The degree of commercialism varies between the public broadcasters of Europe - where some, such as the Estonian ETV at the time of Eurovision Song Contest 2002, were partly financed by commercials - though there are no major differences in production practices. Accordingly, there are also no differences in the features of the programme text between public service and commercial broadcasters.

The pattern analysed here would probably hold true also for programmes that are not live productions. But it would not be suited to all kinds of formats: it might be suited to reality shows like Big Brother, for instance, but not to fiction or drama. Television fiction, such as the soap opera, has narratives that are built around overlapping storylines 
that run parallel to each other, and where the beginnings and endings have different starting points (Kozloff 1987/1990). In this respect, fiction is different from live television entertainment and factual programming, where the repetitive, flat textual structure and visual expressions have become institutionalized in the serialised form of television production prevailing today, and build on certain standardized features in the technical production and in editorial practices. This is especially true of serialized productions such as Bingolotto, but it is also a prominent feature in productions that are repeated more seldom, such as the ESC (each year) and Valvakan (every fourth year). But also in those productions, where there is more time to plan and rehearse, the block structure and the special kind of segmentation become a production practice that is functional for controlling the contingencies of live television production.

\section{Notes}

1. A hybrid channel is commercially financed, but has obligations similar to public service companies through a concessions agreement with state authorities. Thus, such a channel has an intermediate position between public service and commercial broadcasting.

2. For the example of ESC 2002, I am deeply indebted to the observations and material collected by Staffan Ericson (who runs a project on ESC as a media event; cf. Ericson 2002) and Michael Forsman (see especially Forsman 2002), both of whom conducted several interviews with producers, organizers and other production staff, material that I have used here.

3. I will hence not discuss live productions entirely produced outside of the studio, such as sports broadcasts.

4. To take just one example: Iron Chef America is produced at a pace of two programmes each day, allowing the whole season to be recorded in one week (Oldenburg 2005).

5. These practices are not solely confined to the television medium. It is now standard procedure within commercial radio production to occasionally record introductions to songs beforehand (especially before major weekends such as Christmas, in order to save time and to make production more cost-effective).

6. Naturally, this does not necessarily mean that all live studio productions require multi-camera settings. There are obviously examples of single camera settings, not least within the news genres and community television.

\section{References}

Altman, Rick (1999) Film/Genre. London: BFI.

Ang, Ien (1991) Desperately Seeking the Audience. London. Routledge.

Asp, Kent (2004) Svenskt TV-utbud 2003. Stockholm: Granskningsnämnden för radio och TV.

Bakøy, Eva \& Trine Syvertsen (eds) (2001) Sjekking på TV. Offentlig ydmykelse eller bare en lek. En studie av Reisesjekken - programformat, delttakere, produsenter, sponsorer og publikum. Oslo: Unipub.

Barnouw, Erik (1975/1982) Tube of Plenty. The Evolution of American Television (second edition). Oxford: Oxford University Press.

Berger, Arthur Asa (1992) Popular Culture Genres. Theories and Texts. Newbury Park, London \& New Delhi: Sage.

Björkman, Anders (2002) ‘TV4 gjorde valvaka i kortbyxor’, Expressen 16/9 2002.

Bolin, Göran (2002) 'In the Market for Symbolic Commodities. Swedish Lottery Game Show 'Bingolotto' and the Marketing of Social and Cultural Values', Nordicom Review vol. 23:1-2, pp. 177-204.

Bolin, Göran (2004) 'The Value of Being Public Service. The Shifting of Power Relations in Swedish Television Production', Media, Culture \& Society vol. 26:2, pp. 277-287.

Bolin, Göran (2006) 'Visions of Europe. Cultural Technologies of Nation States', International Journal of Cultural Studies, vol 9(2), pp. 189-206.

Bolin, Göran \& Michael Forsman (2002) Bingolotto: produktion, text, reception, Huddinge: MKV (Mediestudier vid Södertörns högskola 2002:1).

Bourdon, Jérôme (2000) 'Live Television is Still Alive: On Television as an Unfulfilled Promise', Media, Culture \& Society, vol. 22, pp. 531-556.

Brants, Kees \& Els De Bens (2000) 'The Status of TV Broadcasting in Europe', in Jan Wieten, Graham Murdock \& Peter Dahlgren (eds) Television Across Europe. London: Sage, pp. 7-22. 
Caldwell, John Thornton (1995) Televisuality. Style, Crisis, and Authority in American Television. New Brunswick, N.J.: Rutgers University Press.

Cawelti, John G. (1976) Adventure, Mystery, and Romance: Formula Stories as Art and Popular Culture. Chicago: University of Chicago Press.

Curran, James (ed.) (2000) Media Organisations in Society. Oxford: Arnold.

Dahl, Hans Fredrik \& Rolf Høyer (2003) Spillet om TV2. Da Norge fikk kommersielt fjernsyn. Oslo. N.W.Damm \& Søn.

Ellis, John (1992) Visible Fictions. Cinema, Television, Video (2nd edition). London \& New York: Routledge

Ellis, John (2000) Seeing Things. Television in the Age of Uncertainty. London \& New York: I.B. Tauris.

Ericson, Staffan (ed.) (2002) Hello Europe! Tallinn Calling! Eurovision Song Contest 2002 som mediehändelse. Huddinge: MKV (Mediestudier vid Södertörns högskola 2002:3).

Feuer, Jane (1983) 'The Onset of Live Television: Ontology as Ideology', in E. Ann Kaplan (ed.) Reading Television. Los Angeles: AFI, pp. 12-22.

Feuer, Jane (1987/1990) 'Genre Study and Television', in Robert C. Allen (ed.) Channels of Discourse, Reassembled. Television and Contemporary Ccriticism. London: Routledge, pp. 113-133.

Fiske, John (1987) Television Culture. London \& New York: Routledge.

Forsman, Michael (2002) 'Direktsändning som teknologi och kulturell form. ESC och konstruktionen av liveness', in Staffan Ericson (ed.) Hello Europe! Tallinn Calling! Eurovision Song Contest 2002 som mediehändelse. Huddinge: MKV (Mediestudier vid Södertörns högskola 2002:3) pp. 69-80.

Genette, Gérard (1987/1997) Paratexts. Cambridge: Cambridge University Press.

Hall, Stuart (1973) Encoding/Decoding in the Television Discourse. Stencilled occasional paper from CCCS nr. 7, Birmingham: Birmingham University/CCCS.

Heat, Steven \& Gillian Skirrow (1977) 'Television: A World in Action', Screen, vol. 18:2, pp. 7-59.

Hirsch, Paul M. (1977) 'Occupational, Organisational, and Institutional Models in Mass Media Research: Toward an Integrated Framework', in Paul M. Hirsh, Peter V. Miller \& F. Gerald Kline (eds) Strategies for Communications Research (Sage annual reviews of communications research vol. 6), Beverly Hills: Sage.

Kozloff, Sarah Ruth (1987/1990) 'Narrative Theory and Television', in Robert C. Allen (ed.) Channels of Discourse, Reassembled. Television and Contemporary Criticism. London: Routledge, pp. 42-73.

Lacey, Nick (2000) Narrative and Genre. Key Concepts in Media Studies. Houndmills: Macmillan.

Marriott, Stephanie (2000) 'Election Night', Media, Culture \& Society, vol. 22, pp. 131-148.

Morse, Margaret (1986) 'The Television News Personality and Credibility: Reflections on News in Transition', in Tania Modleski (red) Studies in Entertainment. Critical Approaches to Mass Culture. Bloomington \& Indianapolis: Indiana University Press, pp. 55-79.

Oldenburg, Ann (2005) 'Pan-to-Pan Combat. Competitive Cooking Before a Live Audience is a Hot Niche on TV', USA Today, May 6, pp. 1E-3E.

Paterson, Richard (2001) 'Work Histories in Television', Media, Culture \& Society. vol. 23, pp. 495-520.

Robins, Kevin \& James Cornford (1992) 'What is 'Flexible'? About Independent Producers?', Screen vol. $33: 2$, pp. $190-200$.

Skovmand, Michael (1992) 'Barbarous TV International. Syndicated Wheels of Fortune', in Michael Skovmand \& Kim Christian Schrøder (eds) Media Cultures. Reappraising Transnational Media, London \& New York: Routledge, pp. 84-103.

Syvertsen, Trine (1996) 'TV2 i Norge 1992-1995. Strategi och programpolitikk i en moderne hybridkanal', in Olof Hultén, Henrik Søndergaard \& Ulla Carlsson (eds) Nordisk forskning om public service. Radio och TV $i$ allmänhetens tjänst. Göteborg: Nordicom, pp. 61-78.

Syvertsen, Trine (1997) Den store TV-krigen. Norsk allmennfjernsyn 1988-96. Oslo: Fagbokforlaget.

Søndergaard, Henrik (1994) DR i TV-konkurrencens tidsalder. København: Samfundslitteratur.

Wieten, Jan, Graham Murdock \& Peter Dahlgren (eds) (2000) Television Across Europe. London: Sage.

Ytreberg, Espen (1999) Allmennkringkastingens autoritet. Endringer i NRK Fjernsynets tekstprodusjon 19871994. Oslo: Institutt for medier og kommunikation.

Åker, Patrik (2002) 'Mediehändelsens plats', in Staffan Ericson (ed.) Hello Europe! Tallinn Calling! Eurovision Song Contest 2002 som mediehändelse. Huddinge: MKV, (Mediestudier vid Södertörns högskola 2002:3), pp. 15-22.

GÖRAN BOLIN, Ph.d., Professor, School of Media, Art and Philosophy, Södertörn University College, goran.bolin@sh.se 